OPEN ACCESS

Spacers to Improve Performance and Porosity of Graphene Based Polymer Electrolyte Fuel Cells

To cite this article: Theo Suter et al 2020 ECS Trans. 98141

View the article online for updates and enhancements. 


\title{
Spacers to Improve Performance and Porosity of Graphene Based Polymer Electrolyte Fuel Cells
}

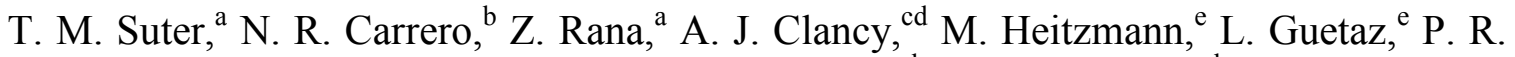 \\ Shearing, ${ }^{\mathrm{a}}$ C. A. Howard, ${ }^{\mathrm{c}}$ G. Gebel, ${ }^{\mathrm{e}}$ P. F. McMillan, ${ }^{\mathrm{d}}$ M. S. P. Shaffer, ${ }^{\mathrm{b}}$ D. J. L. Brett, ${ }^{\mathrm{a}}$ \\ ${ }^{a}$ Department of Chemical Engineering, University College London, London, WC1H 0AJ, \\ U.K. \\ ${ }^{\mathrm{b}}$ Department of Chemistry, Imperial College London, London SW7 2AZ, U.K \\ ${ }^{\mathrm{c}}$ Department of Physics \& Astronomy, University College London, London, WC1H 0AJ, \\ U.K. \\ ${ }^{\mathrm{d}}$ Department of Chemistry, University College London, London, WC1H 0AJ, U.K. \\ ${ }^{\mathrm{e}}$ CEA, Grenoble Alpes, 17 rue des Martyrs, 38000 Grenoble, France.
}

Graphene has been suggested as a potential support material to replace commercial carbon black due to its carbon corrosion resistance. However, graphene-based electrodes typically perform poorly in MEA testing due to restacking of the graphitic sheets. In this study we investigate the introduction of carbon black and their effects on the porosity and current density of graphene-based supports.

\section{Introduction}

Fuel cells provide energy generation alternatives for the traditional fossil fuel dependent transport and energy sectors. ${ }^{1}$ A typical polymer electrolyte fuel cell (PEFC) generates power from the electrochemical reaction between hydrogen and oxygen which forms water. While PEFCs have become increasingly commercialised in the last decade there needs to be a significant cost reduction before the technology sees a much wider uptake. ${ }^{1}$ One of the key methods to reduce costs of PEFCs is to improve device lifetimes. ${ }^{2}$ Carbon support corrosion is one of the key decomposition pathways of a fuel cell, this entails degradation and loss of the carbon support with use, leading to loss of Pt catalyst, ionomer and reduction of proton and electron conduction. ${ }^{3}$ Highly graphitised carbon supports have been reported to have superior carbon corrosion resistance compared to commercial carbon black. ${ }^{4-11}$ This has often been attributed to the $\mathrm{sp}^{2}$ carbon framework being more resistant to oxidation. ${ }^{11}$ Graphene is ideally composed of sheets of $\mathrm{sp}^{2}$ carbon; however, monolayers are rarely used with few layer graphene (FLG) typically acting as the support. When deposited within a catalyst layer the sheets restack during drying, forming a dense, low porosity electrode with low current densities. The potential carbon corrosion benefits of graphene cannot be observed reliably when operated at low current densities, it is therefore imperative to develop methods to control the morphology and layering of graphene based electrodes to mitigate this performance loss. ${ }^{11}$ In this work we report a method of introducing spacers via a scalable fabrication method to control the morphology of graphene based electrodes. This results in an increase in current density and porosity observed under realistic membrane electrode assembly (MEA) testing conditions and using cross sectional SEM.

\section{Experimental}


$\underline{\text { Preparation of sodium-naphthalide solution }}$

A stock sodium-naphthalide solution was prepared to allow for accurate, simple addition of sodium to the corresponding carbon starting material. $23 \mathrm{mg}(1 \mathrm{mmol})$ sodium and $128 \mathrm{mg}(1 \mathrm{mmol})$ dried naphthalene were added to $10 \mathrm{~mL}$ anhydrous DMAc in a $\mathrm{N}_{2-}$ filled glove box, and stirred for 1 day until all sodium had dissolved, forming a darkgreen solution.

\section{$\underline{\text { Synthesis of funtionalised FLG }}$}

Few-layer graphene (FLG) (Cambridge Nanosystems, average lateral size $250 \mathrm{~nm}$ ) was dried/degassed at $400^{\circ} \mathrm{C}$ under high vacuum $\left(\sim 1 \times 10^{-6}\right.$ bar $)$ overnight before being stored in the glovebox $\left(\mathrm{N}_{2}\right)$. FLG $(15 \mathrm{mg}, 1.25 \mathrm{mmol}$ carbon) was introduced in a round bottom flask together with a magnetic glass- coated stir bar. $1.04 \mathrm{~mL}$ of the sodium naphthalide solution was added to the flask and the concentration of FLG in DMAc adjusted to $0.1 \mathrm{M}$ by addition of $11.46 \mathrm{~mL}$ of DMAc $(\mathrm{C} / \mathrm{Na}=12,[\mathrm{Na}]=0.008 \mathrm{M})$. The suspension was stirred at room temperature for 1 day under $\mathrm{N}_{2}$. The mixture was stirred overnight and subsequently 4-bromobenzothioanisole was added to the suspension (76.16 $\mathrm{mg}, 0.38$ $\mathrm{mmol}$ ) to functionalise the carbon nanostructures with functionalities containing thioether groups. To quench any remaining charges, dry $\mathrm{O}_{2} / \mathrm{N}_{2}(20 / 80 \%, \sim 1 \mathrm{~L})$ was bubbled into the solution for $15 \mathrm{~min}$, then stirred overnight under dry $\mathrm{O}_{2} / \mathrm{N}_{2}$. The mixture was filtered through a $0.1 \mu \mathrm{m}$ PTFE membrane and washed thoroughly with DMF, ethanol and water to remove any residual naphthalene and sodium salts formed during the reaction. The product was redispersed in ethylene glycol for the next step.

\section{$\underline{\text { Pt deposition on FLG }}$}

FLG $(30 \mathrm{mg})$ was suspended in ethylene glycol $(30 \mathrm{~mL})$. The suspension was sonicated in a bath sonicator for 10 minutes. The as-described reagent quantities allowed the production of either $40 \mathrm{wt} \%$ or $57 \mathrm{wt} \% \mathrm{Pt} / \mathrm{FLG}$ respectively. Subsequently, $\mathrm{H}_{2} \mathrm{PtCl}_{6} \cdot 6 \mathrm{H}_{2} \mathrm{O}(53.1 \mathrm{mg}, 0.102 \mathrm{mmol}, 106.2 \mathrm{mg}, 0.204 \mathrm{mmol})$ was added to the reaction mixture and stirred for 2 hours at $80^{\circ} \mathrm{C}$. The reaction mixture was allowed to cool down after this time. $\mathrm{NaBH}_{4}(19.3 \mathrm{mg}, 3.85 \mathrm{mmol}, 38.6 \mathrm{mg}, 7.7 \mathrm{mmol})$ was dissolved in ethylene glycol $(2 \mathrm{~mL})$ and slowly added to the FLG dispersion. The mixture was stirred for another $2 \mathrm{~h}$ at room temperature. The mixture was finally filtered through a $0.1 \mu \mathrm{m}$ PTFE membrane and washed thoroughly with DMF and acetone to remove any residual ethyleneglycol. The product was redispersed in an isopropanol:water mixture (1:1, vol:vol) for spraying.

\section{$\underline{\text { RDE electrochemical testing }}$}

Electrochemical data were obtained using an $\mathrm{RDE}$ system with a $\mathrm{Ag} / \mathrm{AgCl}$ reference electrode and a Pt counter electrode in $0.1 \mathrm{HClO} 4$ electrolyte solution. $\mathrm{Pt} / \mathrm{C}$ and $\mathrm{Pt} / \mathrm{FLG}-$ $\mathrm{PhS}$ catalyst inks were made up to be $1 \mathrm{mg} / \mathrm{ml}$ with a Pt loading weight of $35 \mathrm{ug} \mathrm{cm}^{-2}$ in 
an IPA/DI water/Nafion solvent mixture and deposited onto polished glass carbon working electrodes (surface area $0.1963 \mathrm{~cm}^{-2}$ ). Linear sweep voltammograms were obtained between -0.01-1.2 $\mathrm{V}$ at a scan rate of $20 \mathrm{mV} \mathrm{s}^{-1}$ and cyclic voltammograms were obtained between $-0.225-1.05 \mathrm{~V}$ at the same scan rate.

\section{MEA Fabrication}

Catalyst ink was formed by mixing $40 \mathrm{wt} \% \mathrm{Pt}$ on carbon black ( $25 \mathrm{mg}$, HiSpec), $40 \mathrm{wt} \%$ Pt on FLG $(25 \mathrm{mg})$, or a $50 / 50 \mathrm{mix}$ of $57 \mathrm{wt} \% \mathrm{Pt}$ on FLG $(12.5 \mathrm{mg})$ and carbon black (12.5 mg, HiSpec) and with $11 \mathrm{wt} \%$ Nafion water solution $(110 \mathrm{mg})$, of water $(12.5 \mathrm{~mL})$ and IPA (12.5 mL, Sigma Aldrich). This was sprayed directly onto GDL (Freudenberg H23C7) using an ultrasonic spray system (Sono-tek Exactacoat). The bed of the spray coater was heated to $90^{\circ} \mathrm{C}$ during spraying. The flow rate of the Exactacoat was set to 0.4 $\mathrm{ml} / \mathrm{min}$, with an offset serpentine spray pattern. A loading of $0.4 \mathrm{mg}_{\mathrm{Pt}} \mathrm{cm}^{-2}$ was calculated from the mass change on the MEA due to spraying. The graphene GDE was assembled together with Gore Select membrane and a $0.4 \mathrm{mg}_{\mathrm{Pt}} \mathrm{cm}^{-2}$ Hyplat GDE to act as an anode. The MEA was hot pressed at $150^{\circ} \mathrm{C}$.

\section{Fuel Cell electrochemical testing}

Fuel cell testing was performed using a Scribner 850 e Full Cell test system under air/ $/ \mathrm{H}_{2}$ with no back pressure and at $100 \% \mathrm{RH}, 80^{\circ} \mathrm{C}, 1.5 / 3$ was used for the $\mathrm{H}_{2} / \mathrm{O}_{2}$ stoichiometric flow rates. The cell was conditioned by purging with $\mathrm{Ar} / \mathrm{Ar}$ for 10 minutes, followed by $\mathrm{Ar} / \mathrm{H}_{2}$ for 10 minutes, then air/ $\mathrm{H}_{2}$ held at $\mathrm{OCV}$ for 5 minutes. The cells were held at $5 \mathrm{~A}$ for 1 hour, followed by a $\mathrm{Ar} / \mathrm{H}_{2}$ purge, $25 \mathrm{CV}$ 'cleaning' scans were run between 0.06 and $1 \mathrm{~V}$ at $20 \mathrm{mV} / \mathrm{s}$. CV measurements were made between 0.06 and $1 \mathrm{~V}$ at $20 \mathrm{mV} / \mathrm{s}$.

\section{Results and discussion}

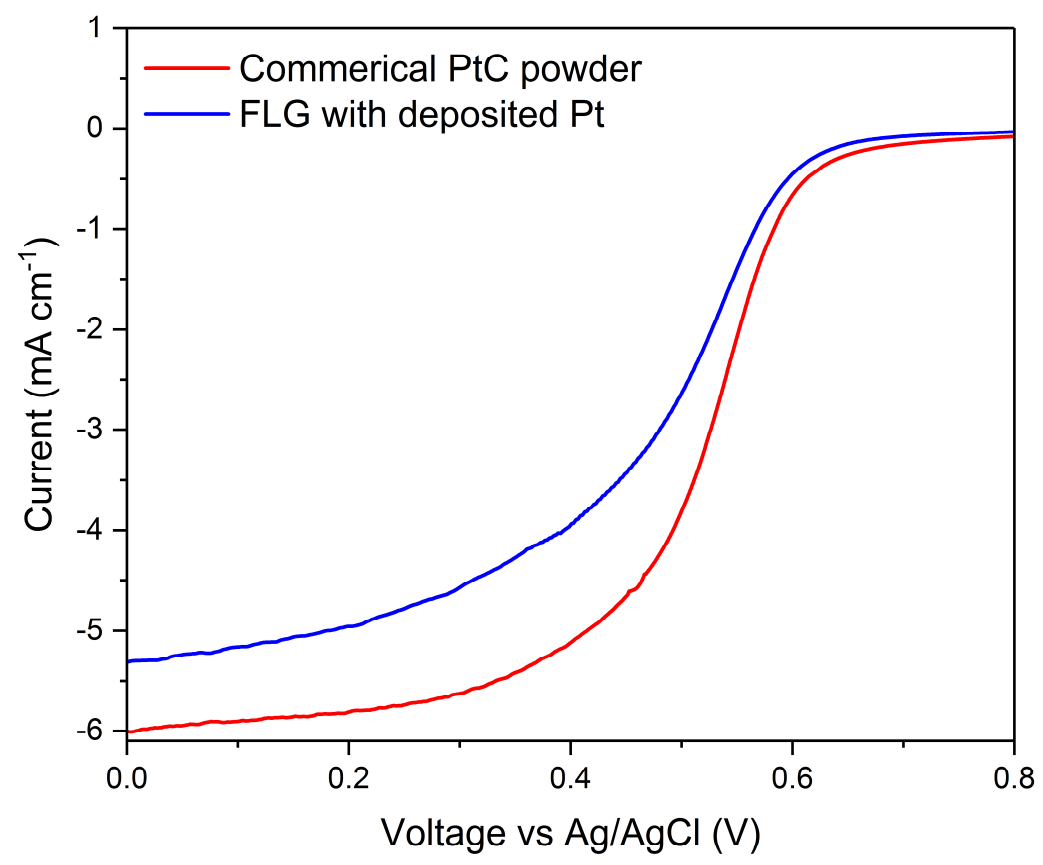


Figure 1. Linear sweep voltammogram (LSVs) of commercial Pt/C powder and FLG with deposited platinum

\section{Graphene based catalyst layer performance}

Figure 1 shows the linear sweep voltammograms (LSVs) of commercial Pt/C and FLG based catalyst material tested in a rotating disk electrode setup (RDE). The onset potential was found to be identical for both support materials, and is typical for platinum based catalysts. ${ }^{12}$ The limiting current of the FLG based material was found to be slightly lower at $5.3 \mathrm{~mA} \mathrm{~cm}^{-1}$ compared to that of commercial $\mathrm{Pt} / \mathrm{C}$ at $6.0 \mathrm{~mA} \mathrm{~cm}{ }^{-1}$. We assign this to differences in platinum nanoparticle size as indicated from ECSA values of 36.8 $\mathrm{m}^{2} \mathrm{gPt}^{-1}$ compared to commercial $75.8 \mathrm{~m}^{2} \mathrm{gPt}^{-1}$. The higher ECSA originates in the differences in deposition method between commercially sourced samples and those synthesised inhouse. From these non-corrosion RDE results the support material has only a small impact on the onset potential and current density.

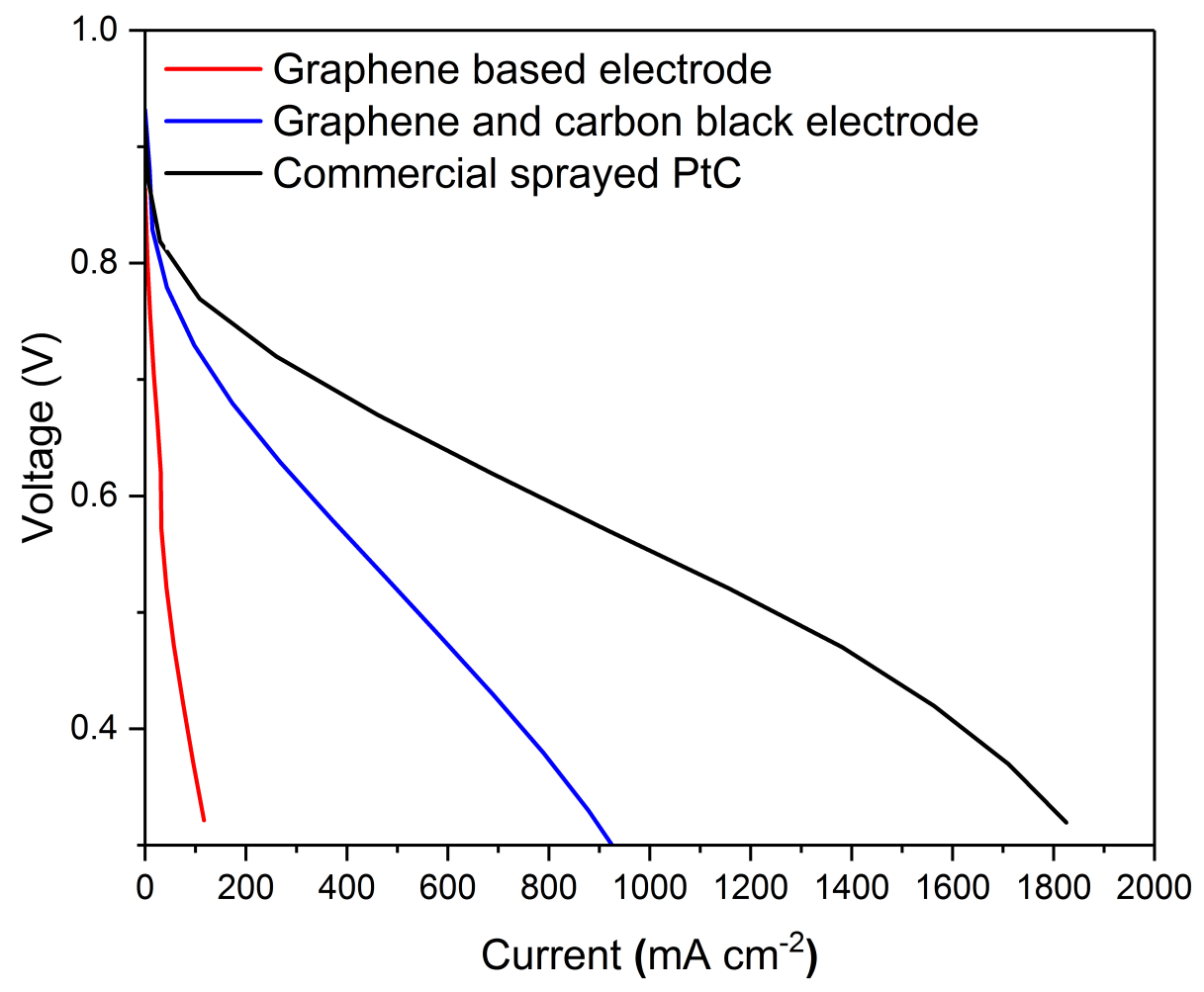

Figure 2. Polarisation curves of graphene-based electrode fabricated with or without spacers.

Figure 2 shows the polarization curves of the same FLG materials shown in Figure 1 but tested in an MEA rather than a RDE. The current density of the simple graphene ink is significantly lower $\left(130 \mathrm{~mA} \mathrm{~cm}^{-2}\right)$ than that for sprayed commercial $\mathrm{Pt} / \mathrm{C}\left(1800 \mathrm{~mA} \mathrm{~cm} \mathrm{~cm}^{-2}\right)$. However, by introducing carbon black spacers the current density, particularly in the mass transport regime is improved to $910 \mathrm{~mA} \mathrm{~cm}^{-2}$. The reduced current density of $\mathrm{Pt} / \mathrm{C}$ compared to graphene in the electrode is typically explained by restacking and aggregation of graphitic layers. ${ }^{13-16}$ It is clear from the relative performance under RDE 
testing compared to MEA testing conditions that this reduced current density is not a property of the support material or catalyst but rather the architecture of the catalyst layer.

\section{Graphene based catalyst layer morphology}

Cross sectional SEM images show the low porosity of the graphene based MEA electrode without the presence of carbon black (Figure 3a). The graphene-based catalyst layer contains no clear micro-, meso- or macroscale porosity. This significantly reduces $\mathrm{Pt}$ utilisation and increases mass transport resistances, which explains the significantly lower current density. The addition of carbon black has resulted in spacing between the FLG sheets, this increases Pt utilisation and due to the natural pore forming nature of carbon black has a larger degree porosity (Figure 3a). However, due to the locations of the platinum on the graphene and the inhomogeneous morphology of the catalyst layer, the performance is still almost half that of commercial $\mathrm{Pt} / \mathrm{C}$.

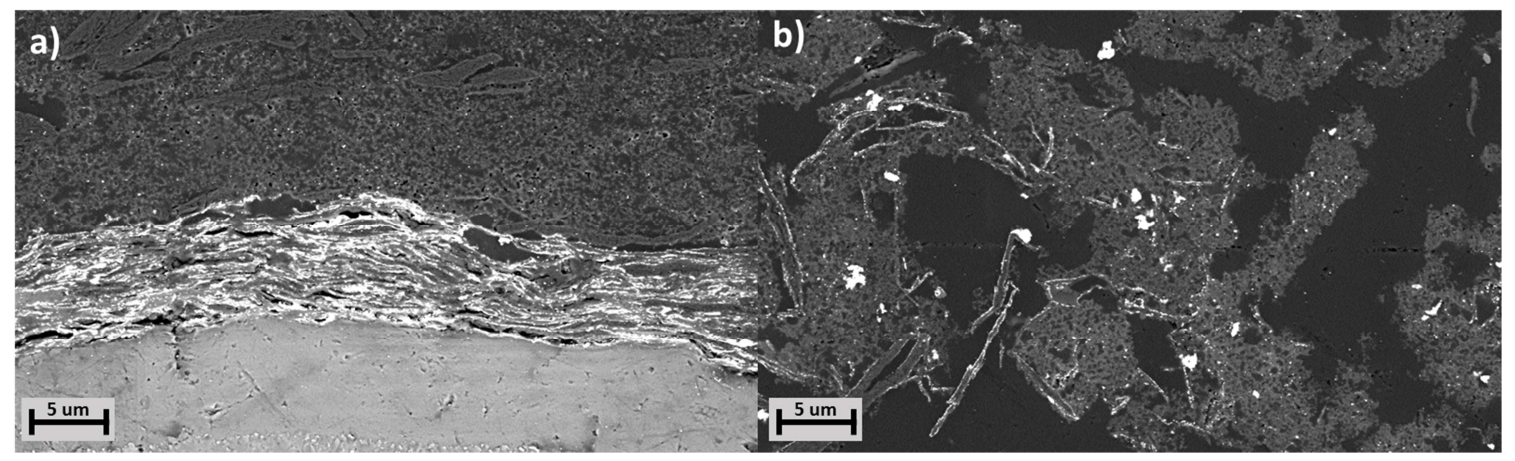

Figure 3. Cross sectional SEM images of graphene-based electrodes, a) catalyst layer fabricated with no spacer, b) catalyst layer fabricated with carbon black spacers.

\section{Conclusion}

In order to improve the current density of scalably produced graphene-based fuel cells and test the carbon corrosion performance under MEA conditions the current density needs to be improved further. Introducing spacers results in a marked improvement in performance. Although they do not yet allow the graphene-based electrodes to compete with commercial materials, they introduce an additional element to the support material that can be tuned to improve carbon corrosion performance. Pore forming additives, not only spacers are required to fabricate a graphene based MEA electrode with the mix of micro-, meso- and macroscale porosity that is typically found in a carbon black based electrode. Without achieving such porosity over multiple length scales scalably manufactured graphene-based electrodes will never achieve efficient Pt utilisation, low mass transport resistance and subsequent high current densities.

\section{Acknowledgments}

This project has received funding from the EU Graphene Flagship under Horizon 2020 Research and Innovation programme grant agreements No. 785219-GrapheneCore2, and 881603-GrapheneCore3, and support from the ESPRC (EP/S01800X/1). 


\section{References}

1. I. E. L. Stephens, J. Rossmeisl, and I. Chorkendorff, Science (80-. ). 354, 1378-1379 (2016).

2. D. Banham, and Y. S. Ye, Acs Energy Lett. 2, 629-638 (2017).

3. O. Lori, and L. Elbaz, Catalysts vol. 5 1445-1464 (2015).

4. T. Kim, T. Xie, W. S. Jung, and B. N. Popov, Int. J. Hydrogen Energy 42, 1250712520 (2017).

5. K. Takahashi, R. Koda, K. Kakinuma, and M. Uchida, J. Electrochem. Soc. 164, F235-F242 (2017).

6. L. Castanheira, W. O. Silva, F. H. B. Lima, A. Crisci, L. Dubau, and F. Maillard, ACS Catal. 5, 2184-2194 (2015).

7. P. Liu, J. Kong, Y. Liu, Q. Liu, and H. Zhu, J. Power Sources 278, 522-526 (2015).

8. Q. He, N. S. Suraweera, D. C. Joy, and D. J. Keffer, J. Phys. Chem. C 117, 2530525316 (2013).

9. L. Xin, F. Yang, Y. Qiu, A. Uzunoglu, T. Rockward, R. L. Borup, L. A. Stanciu, W. Li, and J. Xie, J. Electrochem. Soc. 163, F1228-F1236 (2016).

10. B. T. Sneed, D. A. Cullen, K. S. Reeves, O. E. Dyck, D. A. Langlois, R. Mukundan, R. L. Borup, and K. L. More, ACS Appl. Mater. Interfaces 9, 29839-29848 (2017).

11. E. Antolini, Appl. Catal. B Environ. 123-124, 52-68 (2012).

12. J. Perez, E. R. Gonzalez, and E. A. Ticianelli, Electrochim. Acta 44, 1329-1339 (1998).

13. L. Işıkel Şanlı, V. Bayram, S. Ghobadi, N. Düzen, and S. Alkan Gürsel, Int. J. Hydrogen Energy 42, 1085-1092 (2017).

14. S. Han, D. Wu, S. Li, F. Zhang, and X. Feng, Adv. Mater. 26, 849-864 (2014).

15. Z. Yan, W. Yao, L. Hu, D. Liu, C. Wang, and C. Lee. Nanoscale 7, 5563-5577 (2015).

16. S. Nardecchia, D. Carriazo, M. L. Ferrer, M. C. Gutiérrez, and F. Del. Monte, Chem. Soc. Rev. 42, 794-830 (2013). 